\title{
Article \\ Design of an Artificial Intelligence of Things Based Indoor Planting Model for Mentha Spicata
}

\author{
Hao-Hsiang $\mathrm{Ku}^{1}{ }^{1} * \mathbb{C}$, Cheng-Hsuan $\mathrm{Liu}^{1}$ and Wen-Cheng Wang ${ }^{2}$ (1) \\ 1 Institute of Food Safety and Risk Management, National Taiwan Ocean University, \\ Keelung City 202301, Taiwan; liuchengxuan1997@gmail.com \\ 2 College of Innovation and Entrepreneurship Education, Yango University, Fuzhou 350015, China; \\ wcwang@go.hwh.edu.tw \\ * Correspondence: kuhh@email.ntou.edu.tw
}

Citation: Ku, H.-H.; Liu, C.-H.; Wang, W.-C. Design of an Artificial Intelligence of Things Based Indoor Planting Model for Mentha Spicata Processes 2022, 10, 116. https:// doi.org/10.3390/pr10010116

Academic Editor: Jer-An Lin

Received: 6 December 2021

Accepted: 4 January 2022

Published: 7 January 2022

Publisher's Note: MDPI stays neutral with regard to jurisdictional claims in published maps and institutional affiliations.

Copyright: (C) 2022 by the authors. Licensee MDPI, Basel, Switzerland. This article is an open access article distributed under the terms and conditions of the Creative Commons Attribution (CC BY) license (https:// creativecommons.org/licenses/by/ $4.0 /)$.

\begin{abstract}
In recent years, many large-scale plantings have become refined small-scale or home plantings. The rapid progress of agriculture technologies and information techniques enables people to control the growth of agricultural products well. Hence, this study proposes an Artificial Intelligence of Things (AIoT) based Plant Pot Design for planting edible mint in an office setting, which is called APPD. APPD is composed of intelligent gardens and a cloud-based service platform. An intelligent garden is deployed an Arduino with multiple sensors to monitor and control plant pots of the edible mint, Mentha spicata. The cloud-based service platform provides a Case-Based Reasoning (CBR) inference engine with a database for adjustment influence factors. This study discusses eight growing statuses of Mentha spicata with different illumination, photometric exposure, and moisture content, designed for an office environment. Evaluation results indicate that Mentha spicata with $16 \mathrm{~h}$ redblue lighting and 50\% moisture content makes a maximum 5\% mint extract of the total weight of the mint leaves. Finally, APPD can be a reference model for researchers and engineers.
\end{abstract}

Keywords: Artificial Intelligence of Things; edible mint; mint extract; case-based reasoning

\section{Introduction}

Traditional farming and precision farming are very different from each other in every way. Traditional farming is based on traditional methods and devices for working and growing seasonal crop using farmers' experiences. Traditional farming and traditional large-scale plant factories have gradually begun to develop home-based or mobile-based plant products to establish sustainable ecological agriculture from communities, campuses, roofs, greenhouses, or offices. More and more people have attached importance to organic agriculture and agricultural products. During the intervening decade, researchers have been devoted to developing new technologies to enhance the safety, quality, and quantity of agricultural products [1-3].

In recent years, because of the desire to green the environment or beautify the desktop, the rise of ornamental plants at office desks has led to the development of many small potted plants. As a result, a variety of table plant products have been produced. Vanillabased products are an important choice for everyone. Vanilla, especially mint, has been widely used in foods and beverages. Mint can be planted in a small planting place and can be can be harvested in a short time. Furthermore, mint leaves and flowers will exude fragrance, so it is very suitable for choosing as a table plant, whether it is to be used to green the environment or beautify the desktop.

Traditional greenhouses need to separate a relatively independent space and need to set influence factors for plants to grow. Most greenhouses cannot easily and automatically adjust the growth environment required by plants, and people often need to adjust influence factors. According to the progress and development of information technologies, Artificial Intelligence of Things (AIoT) plays a crucial role in smart agriculture. Smart farming 
is based on information techniques which are composed of controlled influence factors, artificial intelligences, sensors, networks, and mobile devices.

Previous studies discussed and proposed each function individually [1,4-6]. Hence, this study integrates and suggests that five issues are needed to be considered when design an AIoT based Plant Pot for mints in an office setting, including the convenience, illuminance, photometric exposure, moisture content, and digitization $[2,7,8]$.

(1) Convenience. The trend of planting plants is convenient and easy without caring at any time [1]. Plants can be planted using table lights and water in an office setting. To tackle this, a set of small planting pots should be designed for the table.

(2) Illuminance. Plant metabolism requires photosynthesis. Different colors of light have different wavelengths which affect the growth of plants [6,7]. To tackle this problem, multiple color temperatures are needed to be considered and designed for.

(3) Photometric exposure. Light duration not only directly affects photosynthesis, resulting in different plant productivity, but also regulates the growth and development of plants [5]. With different exposure lengths, plants have different flowering times [6]. To tackle this, multiple lighting times are needed to be considered and designed for.

(4) Moisture content. The water in the soil, moisture content, is an important factor for plants to absorb nutrients, avoiding damage to the balance of nutrients due to lack of water or avoiding damage to plant roots caused by too much water. It is an important issue to allow plants to grow at an appropriate moisture content $[8,9]$. To tackle this, moisture content can be kept stable by using a humidity sensor and a water replenisher.

(5) Digitization. It is an important issue to monitor, collect, control, and adjust environmental factors for plant growth $[4,10]$. A variety of sensors are installed to digitize the growth conditions of plants. These can automatically collect and adjust environmental factors for plants [11,12]. To tackle this, a database, an inference engine, and a service platform are designed.

Regarding the aforementioned five design issues, this study proposes an Artificial Intelligence of Things (AIoT) based Plant Pot Design for planting edible mint in an office setting, called APPD. APPD can well handle and tackle problems of convenience, illuminance, photometric exposure, moisture content, and digitization for planting edible mint, Mentha Spicata, in an office setting.

The remainder of this study is organized as follows. Section 2 describes the related work. Section 3 describes the infrastructure and components of APPD. Section 4 describes the implementation and evaluations of APPD. Finally, Section 5 gives the concluding remarks.

\section{Literature Review}

In recent years, because of advances in agricultural technology, people can easily set and adjust growth factors of plants. Furthermore, Information Technology (IT) drives the transformation of traditional agriculture. Intelligent planting uses AIoT sensors to detect raw data and adjust various factors automatically, which make farming easy, economical, minimizes labor costs, improves crop yields, and provides better production [1]. Hence, researchers have been devoted to finding improved methods to achieve the most efficient production methods. Growth factors of plants can be roughly discussed and divided into three classes, which are intelligent planting, illuminance and photometric exposure, and moisture content.

\subsection{Intelligent Planting}

Intelligent planting uses multiple sensors and automation devices to automatically adjust various growth factors. After analyzing collected raw data, devices are adapted to optimize the growth environment of plants. I. Abbas et al. discussed that target detection systems have been developed using advanced methods, such as laser and vision scanning systems or ultrasound, infrared, and spectrum systems to enhance planting [10]. The 
authors developed a real-time target detection spray system for the detection of geometric properties of tree plants which were reviewed in detail. A. González-Briones et al. proposed a Multi-Agent System (MAS) to automate gathering and managing information from potato crops to provide a precision irrigation system [8]. The use of MAS in rural areas provides a considerable saving of resources and improves the efficiency and effectiveness of agricultural production systems. A.F. Subahi et al. proposed a highly scalable intelligent system for controlling and monitoring greenhouse temperature using IoT technologies in greenhouse farming, allowing reduction of the immediate impact of external climatic conditions [13]. The proposed system was designed for increased and improved productivity.

\subsection{Illuminance and Photometric Exposure}

Plants use different illuminance, photometric exposures, and exposure times to control the effect of light on plant growth [5]. As an important parameter of plant growth, light intensity is one of the important factors that affects plant growth and development, morphological establishment, and accumulation of functional chemical substances [6]. Y. Tang et al. designed a system for greenhouse plants using 3D supplementary lighting, which can be auto-switched to sunlight or LED for different kinds of weather conditions [14]. The system for greenhouse plants used intelligent supplementary illumination, which can supply light to every leaf with a hybrid sunlight-LED system based on the Internet of Things. F. He et al. aimed to address the optimal plant light intensity problem, designing an expert technology database to store the empirical values of real-time light intensities [6]. The authors used a parallel particle swarm optimization algorithm to identify the optimal locations an identify the number of LED fill lights needed. M.R. Sabzalian et al. used different LED lights, which were lit with 100\% red, 100\% blue, $70 \%$ red, plus 30\% blue, or $100 \%$ white LED. The authors cultivated Mentha piperita, Mentha spicata, and Mentha long folia, lentil, basil, and four ornamentals to test the effect of various LED lights on plant productivity compared with field and greenhouse conditions [7]. A.H.A Farooqid et al. designed the $8 \mathrm{~h}, 16 \mathrm{~h}$, and $24 \mathrm{~h}$ photoperiodic treatments to observe the growth behaviors, essential oil contents, oil compositions, and essential oil biosyntheses [15]. The results indicated that the oil concentration and biogenesis was maximal in short-day plants. Different photoperiodic treatments had little influence.

\subsection{Moisture Content}

Moisture content is the quantity of water contained in a material. Different soil and water content will affect plant growth. B. Mason et al. modeled an intelligent irrigation system that included a wireless sensor network and controllable valves applied on an urban tomato garden of nine climatic regions of the United States [9]. The authors created the Conventional-Scenario Intelligent-Scenario Index to compare the overall performance of an intelligent irrigation strategy to a conventional one. M. Hadipour et al. proposed an innovative technique of a Multi-Intelligent Control System (MICS) of a water pump and pump station, which is practically designed, set up, and used in the agricultural sector [16]. The main component of MICS consists of three control systems, including the electro-pump controller, a gauge for the water level in the reservoir, and an alarm control system for water management in the agriculture. N.K. Nawandar and V.R. Satpute proposed a low-cost intelligent system for smart irrigation with the functions of admin mode for user interaction, one-time setup for irrigation schedule estimation, neural-based decision-making for intelligent support, and remote data monitoring [17]. A sample crop test-bed was chosen to present the results of the proposed system, that included irrigation scheduling, neural net decision-making, and remote data viewing.

Of the above-mentioned related studies, most discussed planting related topics using information technology, which shows a summary of the differences of the literature review as Table 1. 
Table 1. The summary of the differences of the literature review.

\begin{tabular}{|c|c|c|c|c|c|}
\hline Technology & Convenience & Illuminance & Photometric Exposure & Moisture Content & Digitization \\
\hline Internet of Things (IoT) & $\checkmark[1,10,13]$ & & & $\checkmark[8,9,16]$ & $\checkmark[6,8-10,13]$ \\
\hline Informational Assistance & & $\checkmark[5,7,14]$ & $\checkmark[5,15]$ & & \\
\hline Artificial Intelligence & & $\checkmark[6,15]$ & & $\checkmark[17]$ & $\checkmark[17]$ \\
\hline Data Analysis & & $\checkmark[6]$ & & $\checkmark[9,16,17]$ & \\
\hline
\end{tabular}

The aforementioned studies aim at monitoring and controlling the greenhouse regarding temperature, humidity, carbon dioxide, and other factors that influence plant growth. This study designs an easy way to handle the growing of edible mint well, in an office setting, and considers problems of convenience, illuminance, photometric exposure, moisture content, and digitization.

\section{Method}

Artificial Intelligence of Things (AIoT) based Plant Pot Design for planting edible mint in an office setting, which is called APPD. APPD is composed of intelligent gardens and a cloud-based service platform. Figure 1 illustrates the system architecture and related components of APPD. An intelligent garden deploys an Arduino with multiple sensors to monitor and control plant pots. The cloud-based service platform provides an inference engine and a database with multiple triggers. Related components and functions are described as follows.

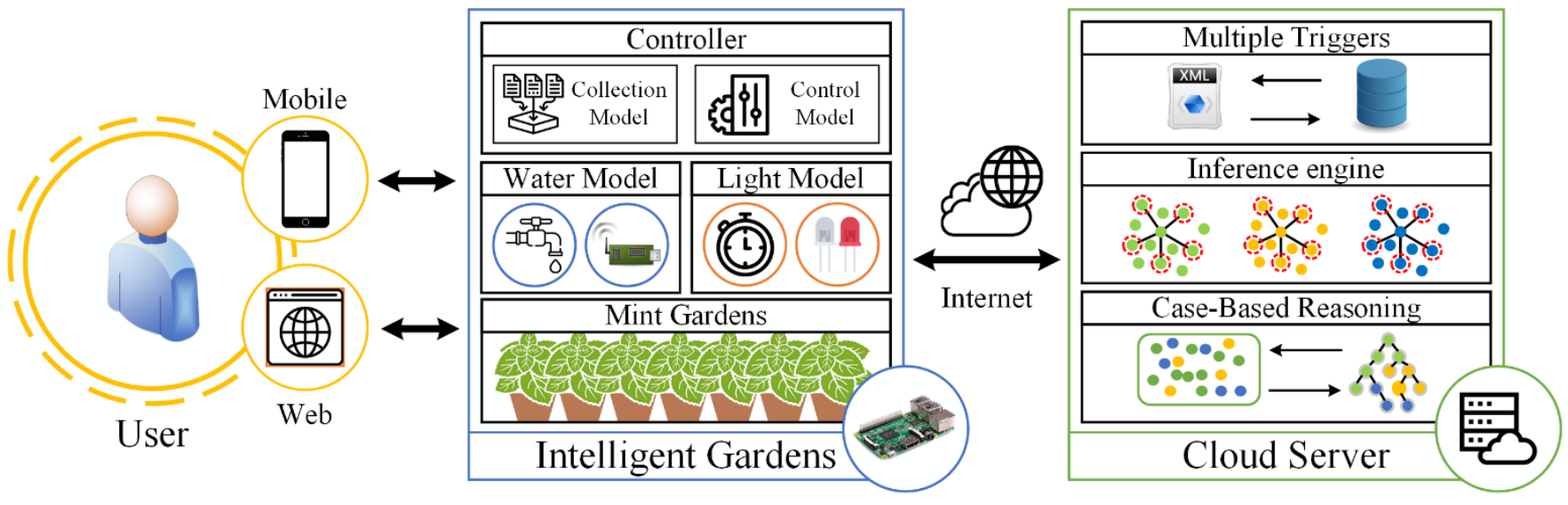

Figure 1. AIoT-based Edible Mint Garden.

\subsection{Growth Factor Selection and Evaluation of Edible Mint}

The growth factors of edible mint are illuminance, photometric exposure, moisture content, and temperature $[5,18]$. The selected plant is the Mentha spicata, a kind of edible mint. The temperature is $26{ }^{\circ} \mathrm{C}$ in an office setting. The wavelength of red LED and red-blue LED are suitable wavelengths that plants can use [7]. In order to compare the growth and development morphology of mints, mints are subjected to different exposures to test the total amount of leaf growth and increase the number of stolon stems $[4,19]$. The photoperiod is defined as the period of daily illumination received by an organism. The photoperiod time is, respectively, a long time, $16 \mathrm{~h}$, and a short time, $8 \mathrm{~h}$. The moisture contents are $75 \%$ and $50 \%$ to test the growing scenario of Mentha spicata. Hence, Table 2 lists the eight experimental testing environments. 
Table 2. Setting testing parameters.

\begin{tabular}{ccccccc}
\hline & \multicolumn{2}{c}{ Illumination } & \multicolumn{2}{c}{ Photoperiod Exposure } & \multicolumn{2}{c}{ Moisture Content } \\
\cline { 2 - 6 } & Red & Red-Blue & $\mathbf{1 6 ~ h}$ & $\mathbf{8 ~ h}$ & $\mathbf{5 0 \%}$ & $\mathbf{7 5 \%}$ \\
\hline R508A & $\checkmark$ & & & $\checkmark$ & & $\checkmark$ \\
\hline R508B & $\checkmark$ & & $\checkmark$ & $\checkmark$ & $\checkmark$ \\
\hline R758A & $\checkmark$ & $\checkmark$ & & $\checkmark$ & \\
\hline R758B & $\checkmark$ & & & $\checkmark$ & $\checkmark$ & \\
\hline R5016A & & $\checkmark$ & $\checkmark$ & & $\checkmark$ \\
\hline R5016B & & $\checkmark$ & & & $\checkmark$ & \\
\hline R7516A & & $\checkmark$ & $\checkmark$ & & $\checkmark$ & $\checkmark$ \\
\hline R7516B & & $\checkmark$ & $\checkmark$ & & & \\
\hline
\end{tabular}

\subsection{Intelligent Gardens}

Intelligent gardens deploy multiple sensors and automation devices to monitor and check suitable environments for mints in an office setting. Two issues need to be discussed, including finding out influential growth factors of mints and setting out intelligent mini landscape gardens. An Intelligent mini landscape garden includes AIoT hardware and software. The controller of AIoT is based on an embedded system, a Raspberry Pi and an Arduino, to connect and control multiple sensors in an intelligent garden. The controller monitors and gets raw data from intelligent mini landscape gardens. The growth factors of mints include temperature, soil, light, air, and water.

After data collection, growth factors are retrieved, selected, and weight factors constructed by the cloud server's inference engine. Intelligent gardens construct growth strategies for mints. The construct strategy is illustrated as Figure 2. The strategy of important factors is constructed by triggers provided by the cloud server. The Gwi and Gwk are the related weights between nodes i and k, respectively. The detailed formulas are shown as Formulas (1)-(3).

$$
\begin{gathered}
G w i=\sum_{j=1}^{r} w_{i j} \\
G w k=\sum_{j=1}^{r} w_{k j} \\
G w_{\text {subNode }}=\frac{G w}{\text { sum(the parent's subNode) }}
\end{gathered}
$$

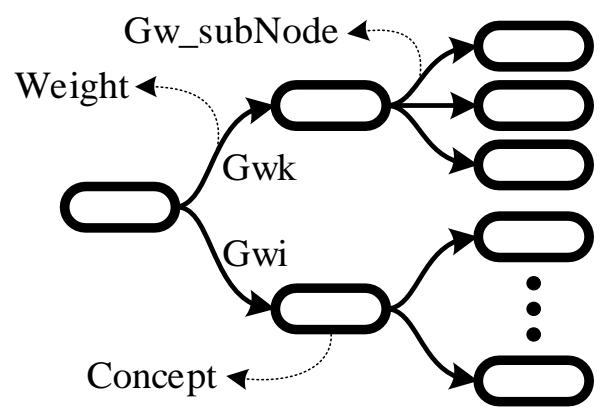

Figure 2. The constructed strategy of important factors.

Because the planting environment is an office, the temperature is $26^{\circ} \mathrm{C}$. The designs of intelligent gardens for mints need to set and control parameters of illuminance, photometric exposure, and moisture content. Hence, to evaluate the illuminance and photometric exposure of plants, APPD provides stable lights by LED. LED can provide stable lights with low power consumptions and low radiant heat. The wavelength of red light, blue light and red-blue light LED usually can be used by plants [5,7]. Hence, APPD automatically 
turns on and off LED lights for planted mints. To evaluate the moisture content of plants, APPD provides an automatic irrigation module, which automatically detects the moisture content and triggers the irrigation module to maintain the moisture content of plants. Raw data, sensed by sensors, are stored into a database in the cloud server. Sensed data not only can be displayed for users but also can be reasoned by the cased-based reasoning inference engine. Figure 3 illustrates the deployment of an intelligent garden. A controller interacts with a user, a cloud server, and intelligent gardens. Table 3 lists a summary of the used sensors. Based on the above design patterns, an intelligent garden can automatically control AIoT devices with growth factors, including illuminance, photometric exposure, and moisture content. If any exception occurs, the APPD will automatically adjust back to the original state and send a notification message to the user.

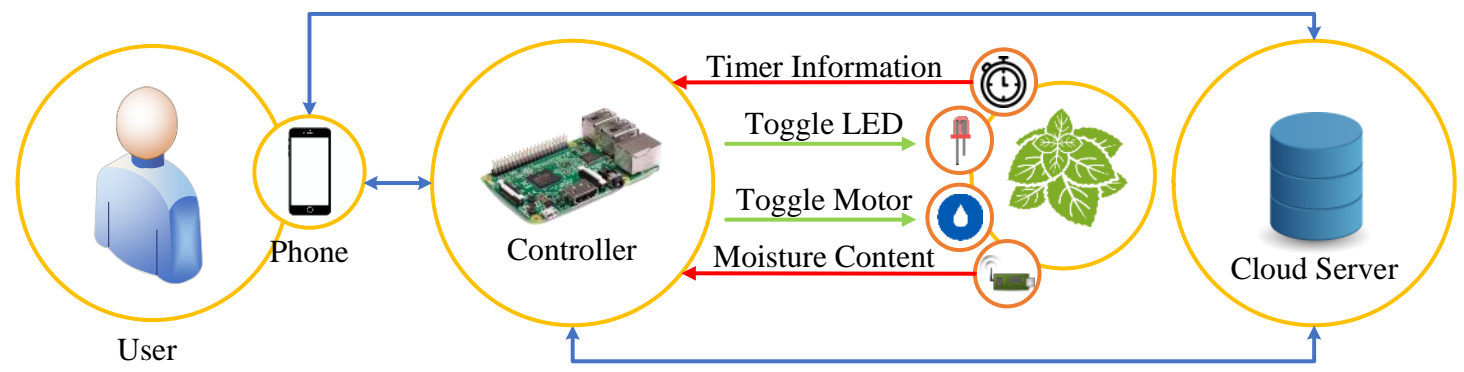

Figure 3. The deployment of an intelligent garden.

Table 3. Summary of used sensors.

\begin{tabular}{cccccc}
\hline & Sensor & Voltage & Current & Sensitivity Ranges & Output \\
\hline Temperature & DHT22 & $3-5.5 \mathrm{~V}$ & $2.5 \mathrm{~mA}$ & $-40-80{ }^{\circ} \mathrm{C} \pm 0.5{ }^{\circ} \mathrm{C}$ & Digital signal \\
\hline Moisture & SEN0193 & $3.3-5.5 \mathrm{~V}$ & $5 \mathrm{~mA}$ & $0-100 \% \mathrm{RH}$ & $\begin{array}{c}\text { Analog } \\
\text { signal }\end{array}$ \\
\hline Illuminance & ISL29125 & $3.3 \mathrm{~V}$ & $56 \mu \mathrm{A}$ & $\begin{array}{c}\text { Range } 0=5.7 \mathrm{~m} \text { lux to } 375 \text { lux } \\
\text { Range } 1=0.152 \text { lux to } 10,000 \text { lux }\end{array}$ & I2C \\
\hline
\end{tabular}

\subsection{A Cloud-Based Service Platform}

The cloud-based service platform is responsible for storing sensed data and reason out the weights of the influential factors. The core of the inference engine is the case-based reasoning mechanism with a big data database.

\section{Inference Engine}

The inference engine of APPD is based on the Case-Based Reasoning (CBR) mechanism. Case-based reasoning is the process of solving new problems based on solutions of past problems [20]. Case-based reasoning uses four processes, which are retrieve, reuse, revise, and retain. Hence, APPD uses eight kinds of data, which are ID, time stamp, moisture content, illuminance, light time, solid matters, ethanol, and photos. Case-based reasoning can evaluate a new case and find out the most similar old case. All data of the most similar old case can be referenced for the new case. Furthermore, data can set thresholds and generate conditional expressions and rules. The generated rules can be triggers in the inference engine. The produced triggers will be delivered and set to intelligent gardens. Figure 4 illustrates the detail working flow of the inference engine. The control steps are described as follows. 


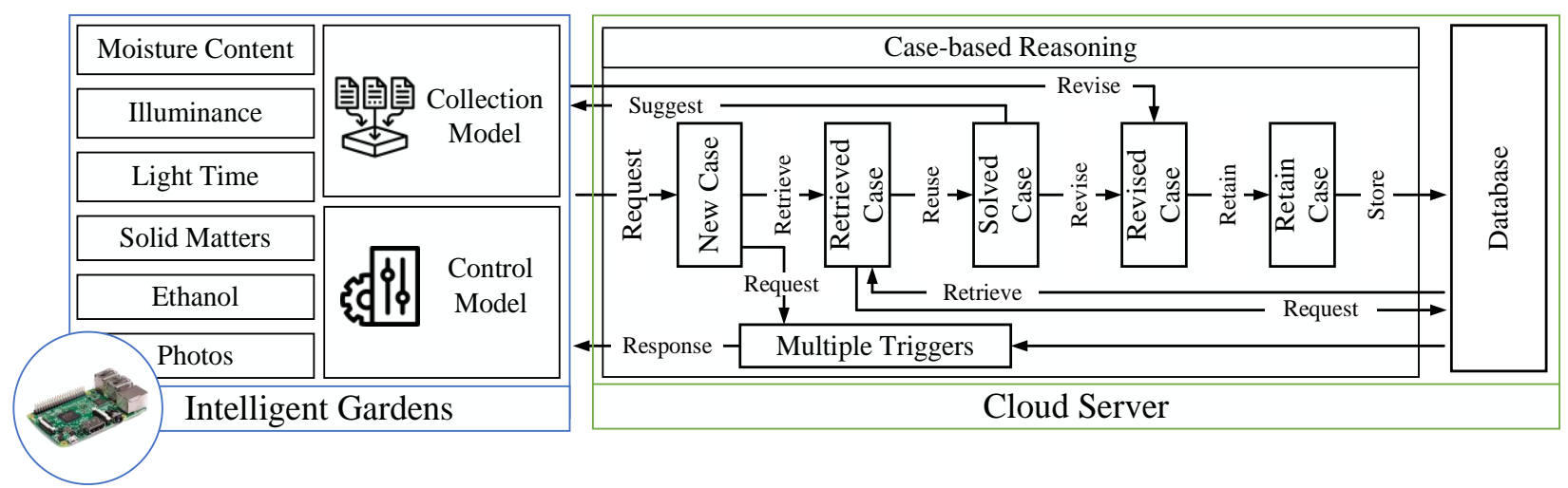

Figure 4. The working flow of the inference engine.

The case-based reasoning mechanism will retrieve cases from the database to find the most similar case. The searching scheme is based on the Euclidean Distance (ED) method, as Formula (4) [20].

$$
E D_{i}=\sqrt{\sum_{k=1}^{n}\left({ }_{i} C_{k}^{\text {old }}-C_{k}^{\text {new }}\right)^{2}}, \forall i \in \operatorname{case}\{1, \ldots, i\}
$$

- $\quad E D i$ : The Euclidean Distance between new case and old Case $i$.

- Case $i$ : The $i$ th case.

- $\quad C_{k}^{\text {new }}$ : The $k$ th attributes of the new case, for $k=1, \ldots, n$.

- $\quad{ }_{i} C_{k}^{\text {old }}$ : The $k$ th attributes of the experienced case, old case, for $k=1, \ldots, n$.

The case-based reasoning mechanism searches a new case and compares it with experienced cases in the database. Every experienced case generates an $E D$ value. The case with the smallest value of the $E D$ is the most similar case and then the case-based reasoning mechanism uses the most similar case as the modification reference of the next reasoning step. The formula is described as Formula (5)

$$
\mathrm{CBR}=\min \left\{E D_{i}\right\}, \forall i \in \operatorname{case}\{1, \ldots, i\}
$$

When the case-based reasoning mechanism finishes the Retrieve phase and Reuse phase, the case-based reasoning mechanism applies this case to the new problem. Based on the reasoning results, the mechanism gives the suggestion for users. Finally, the case-based reasoning mechanism stores the final reasoned case into the database. As the volume of the experienced cases increases, the case-based reasoning mechanism is capable of determining more accurate reasoning. APPD can automatically set parameters, including the time stamp, moisture content, illuminance, light time, solid matters, and ethanol, to intelligent gardens by the reasoned case.

\subsection{Big Data Database}

The big data database is responsible for storing different types and formats of data. Sensed data of APPD includes ID, time stamp, moisture content, illuminance, light time, and photos from intelligent gardens with different formats. When data are sensed and stored into the database, these data will be classified as different data types. Data will be managed by Hive and Impala, controlling data by query planner, query coordinator, and query exec engine [21]. The manipulated data will be stored into Hbase. The file store is based on Hadoop and Hbase. Finally, the data will be managed by Hadoop Distributed File System (HDFS). The detailed work-flow is shown in Figure 5. 


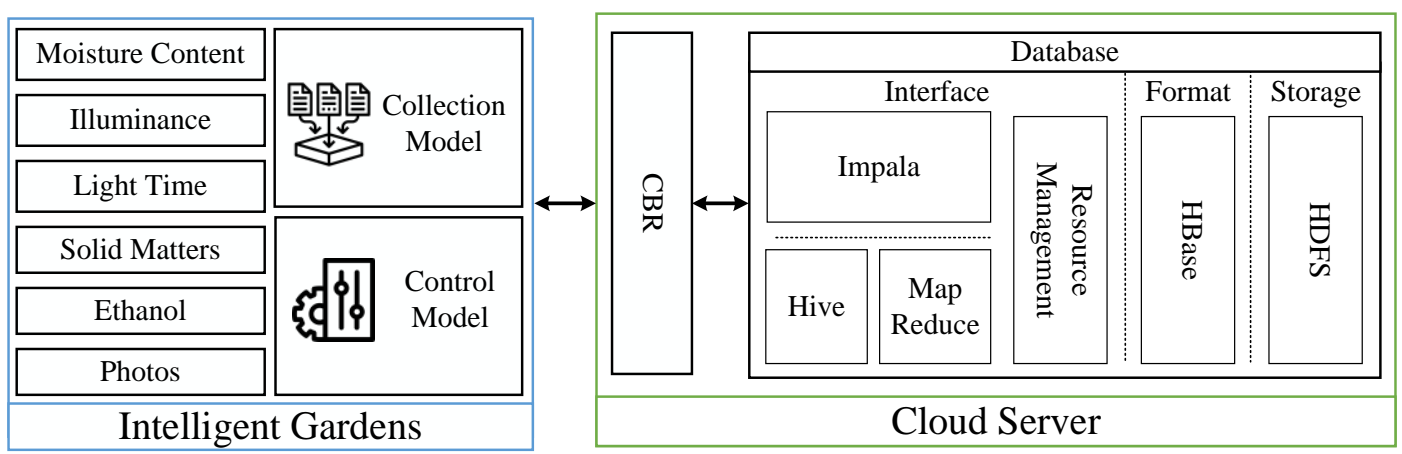

Figure 5. The database of APPD.

\section{Results and Discussion}

This section introduces developments of an Artificial Intelligence of Thing (AIoT) based Plant Pot Design for planting edible mint in an office setting (APPD) and the experimental testing environment, which includes the selected plant, illuminance, photometric exposure, and moisture content. Four control factors for plant growth are illumination, photoperiod exposure, moisture content, and temperature. This study focuses on the office setting. The limitations are described as follows. (1) The mint is Mentha spicata. (2) The temperature is $26^{\circ} \mathrm{C}$. (3) The photoperiod exposures are $8 \mathrm{~h}$ or $16 \mathrm{~h}$. Collecting growth factors data, such as growth height of the mint, the number of mint leaves, and the amount of mint extract extracted, are used to evaluate environmental factors for mint growth. The mint extract is extracted by Rotary Evaporator method [22,23]. Figure 6 illustrates the work-flow of the extraction processes, including preprocessing phase, extraction phase, and result phase.

The experiment is based on the ethanol extraction method. The mint was ground to

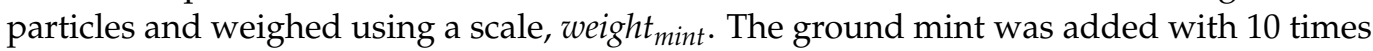
$95 \%, 75 \%$, and $70 \%$ ethanol, separately. The mixture was then heated at $60{ }^{\circ} \mathrm{C}$ of the solvent for $3 \mathrm{~h}$. The mixture was filtered with Advantec $5 \mathrm{C}$ filter paper. The residue was extracted in triplicate. Each extract was collected and combined. The solvents were removed under vacuum, while the concentrate was freeze-dried (Kingmech Co., Ltd.,

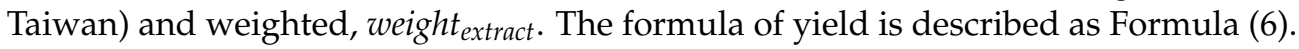

$$
\operatorname{Yield}(\%)=\frac{\text { weight }_{\text {extract }}}{\text { weight }_{\text {mint }}} \times 100
$$

The extraction results are listed by Tables 4 and 5. Table 4 lists the mint extract content extracted from different concentrations of ethanol, which indicates $70 \%$ ethanol is with $3.61 \%$ extract contents. Table 5 lists the different proportions of solid matter, which indicates 1:6 is with $4.90 \%$ extract contents. Due to the results of Tables 4 and 5, the experimental testing is based on 70\% ethanol and 1:6 solid matter. Furthermore, this study tests the extract extraction rate of the red light and the red-blue light, as indicated in Tables 6 and 7. Experimental results indicate that the mints, the Mentha spicata, with the suitable growing environment are with $16 \mathrm{~h}$ red-blue light illumination and 50\% moisture content. Table 7 indicates that mints can be extracted lower $45.97 \%$ extract content under red light illuminations. Hence, evaluation results indicate that the red-blue lights are better than red lights. 


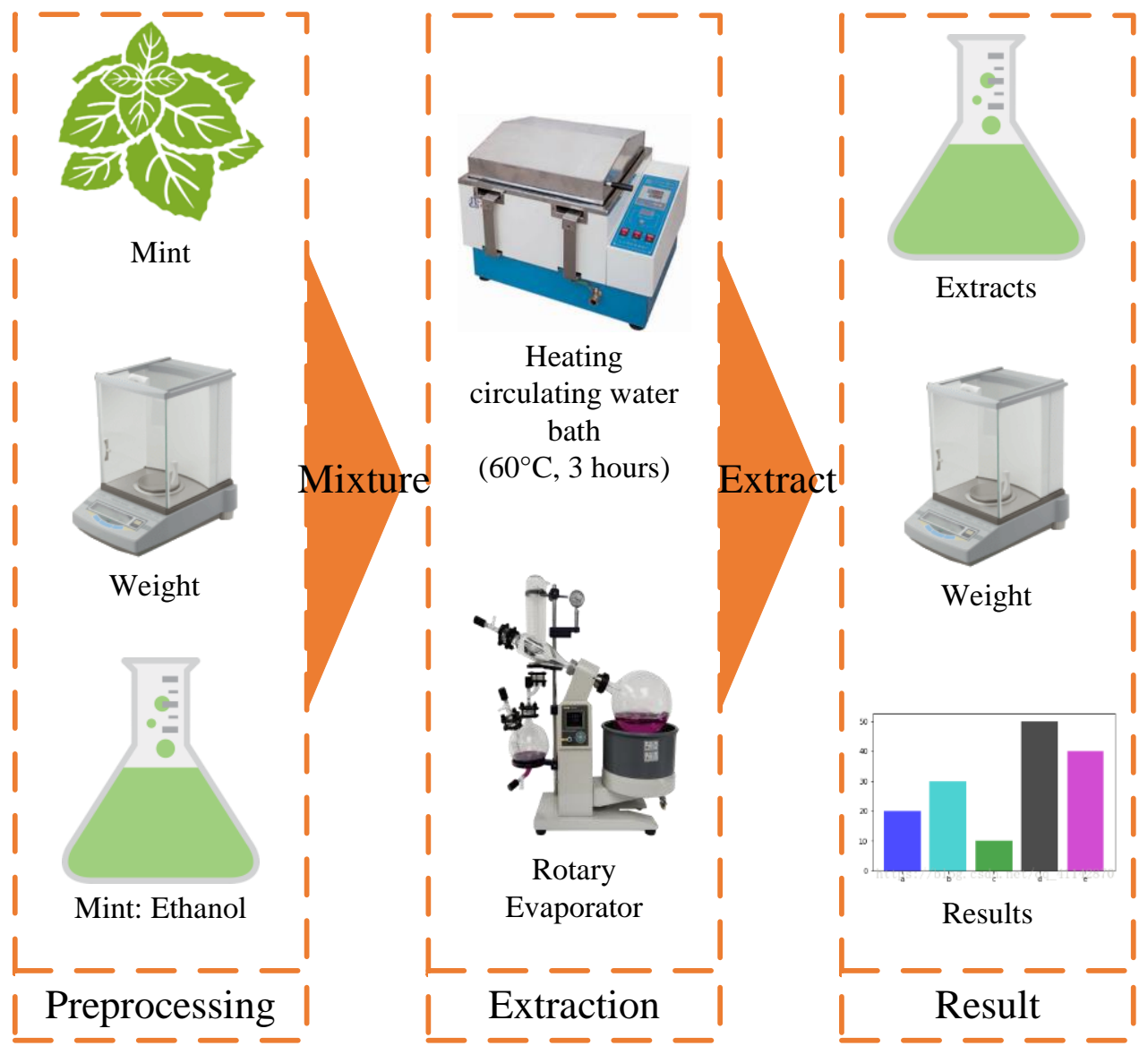

Figure 6. Extraction processes of the mint extract.

Table 4. The extract content extracted from different concentrations of ethanol.

\begin{tabular}{cccc}
\hline Ethanol (\%) & Mint (g) & Weight of the Concentrate after Extraction (g) & Yield (\%) \\
\hline \multirow{3}{*}{95} & 3 & 0.042 & 1.40 \\
\cline { 2 - 4 } & 3.06 & 0.037 & 1.21 \\
\cline { 2 - 4 } 75 & 3.07 & 0.035 & 1.14 \\
\hline \multirow{3}{*}{7.02} & 0.068 & 2.25 \\
\hline \multirow{2}{*}{70} & 3.01 & 0.060 & 1.99 \\
\cline { 2 - 4 } & 3.01 & 0.072 & 2.39 \\
\hline & 3.02 & 0.096 & 3.18 \\
\hline & 3.02 & 0.092 & 3.07 \\
\hline
\end{tabular}

The experimental design is based on Table 2, which are with the eight individual spaces and with different illuminations, photoperiods of exposure, and moisture contents. The individual experimental testing environment is shown in Figure 7. This study discusses eight growing statuses of the Mentha spicata with different illuminations, photometric exposures, and moisture contents, designed for an office environment. Evaluation results indicate the following conditions. (1) Because it is planted in the office, there are inherent specific constrictions. The temperature is $26^{\circ} \mathrm{C}$ in an office setting. The photoperiod time is, respectively, a long time, $16 \mathrm{~h}$, and a short time, $8 \mathrm{~h}$. (2) Results indicate the best extraction effect is based on $70 \%$ ethanol and 1:6 solid matter. (3) Mentha spicata is with $16 \mathrm{~h}$ red-blue lighting and 50\% moisture content to make the maximum 5\% mint extract of the total 
weight of the mint leaves. (4) When Mentha spicata is grown under red light, the extracted mint extract content is less than $2.18 \%$.

Table 5. The different proportions of solid matters.

\begin{tabular}{cccc}
\hline \multirow{2}{*}{$\begin{array}{c}\text { Proportion } \\
\text { (Mint: Ethanol) }\end{array}$} & Mint (g) & $\begin{array}{c}\text { Weight of the Concentrate } \\
\text { after Extraction (g) }\end{array}$ & Yield (\%) \\
\hline \multirow{2}{*}{$1: 5$} & 0.53 & 0.017 & 3.21 \\
\cline { 2 - 4 } & 0.56 & 0.020 & 3.57 \\
\hline \multirow{2}{*}{$1: 6$} & 0.54 & 0.014 & 2.59 \\
\hline & 0.58 & 0.027 & 4.66 \\
\hline \multirow{2}{*}{$1: 7$} & 0.51 & 0.025 & 4.90 \\
& 0.55 & 0.025 & 4.55 \\
& 0.54 & 0.012 & 2.22 \\
\hline & 0.53 & 0.012 & 2.26 \\
\hline
\end{tabular}

Table 6. Mints are with red-blue LED lights.

\begin{tabular}{cccc}
\hline ID & Mint (g) & Weight of the Concentrate after Extraction (g) & Yield (\%) \\
\hline RB508A & 0.55 & 0.011 & 2.00 \\
\hline RB508B & 0.52 & 0.013 & 2.50 \\
\hline RB758A & 0.50 & 0.009 & 1.80 \\
\hline RB758B & 0.54 & 0.010 & 1.85 \\
\hline RB5016A & 0.58 & 0.028 & 4.83 \\
\hline RB5016B & 0.52 & 0.026 & 5.00 \\
\hline RB7516A & 0.55 & 0.023 & 4.18 \\
\hline RB7516B & 0.57 & 0.023 & 4.04 \\
\hline
\end{tabular}

Table 7. Mints are with red LED lights.

\begin{tabular}{cccc}
\hline ID & Mint (g) & Weight of the Concentrate after Extraction (g) & Yield (\%) \\
\hline R508A & 0.54 & 0.008 & 1.48 \\
\hline R508B & 0.55 & 0.012 & 2.18 \\
\hline R758A & 0.56 & 0.008 & 1.43 \\
\hline R758B & 0.52 & 0.006 & 1.15 \\
\hline R5016A & 0.56 & 0.011 & 1.96 \\
\hline R5016B & 0.57 & 0.009 & 1.58 \\
\hline R7516A & 0.56 & 0.007 & 1.25 \\
\hline R7516B & 0.55 & 0.007 & 1.27 \\
\hline
\end{tabular}




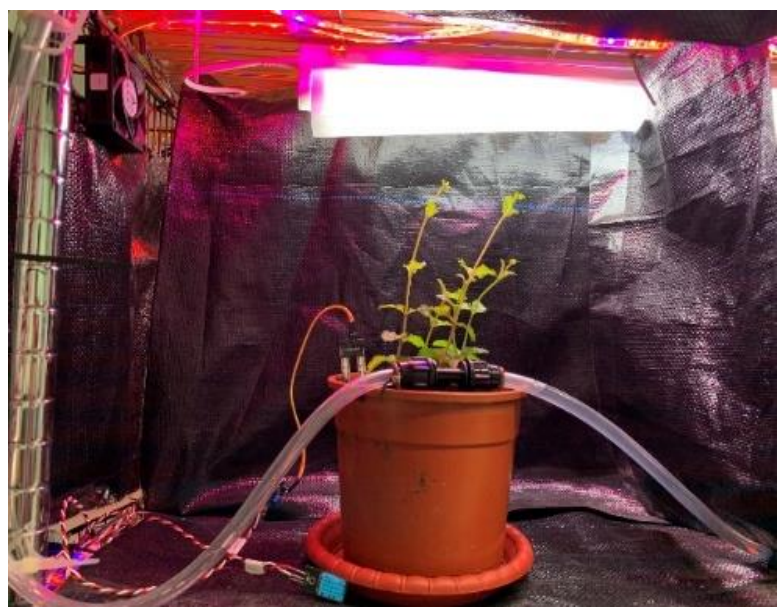

Figure 7. An individual space for a mint plant.

Figure 8 illustrates the implementation of an APPD system design. The data types of sensed data are listed as Table 8. Data are tagged, stored, retrieved, delivered, and classified using Extensible Markup Language (XML). Figure 9 presents an example of XML-based message delivery. The detail work-flow is described as Figure 5. The user can interact with Raspberry Pi, which can read data from intelligent gardens. The Raspberry $\mathrm{Pi}$ connects and controls sensors to read and sense data from plant pots. The user can well handle the growth statuses of plant pots. Furthemore, user interfaces are designed by Responsive Web Design (RWD) techniques. The user interfaces will automatically be adapted by users' devices and screen sizes to ensure usability and satisfaction. Figure 10 shows system interfaces of intelligent gardens via a computer and a smart phone. Figure 11 shows the detail sensed data of APPD. The dashboard shows the statuses of sensors and plant pots, including the illuminance, photometric exposure, moisture content, and so on. The information displayed on this interface is to show whether sensors are operating normally or not. Monitoring the data ensures the accuracy of the APPD model when calculating the data to adjust and trigger the light and water sensors. The illuminance and photometric exposure are controlled by the timer. When moisture contents are sensed by AIoT sensors, APPD will automatically trigger the water model to increase the water content. APPD not only triggers sensors, but also monitors plant pots automatically. Users can easily monitor and observe the growth statuses of plant pots and working conditions of sensors by APPD.

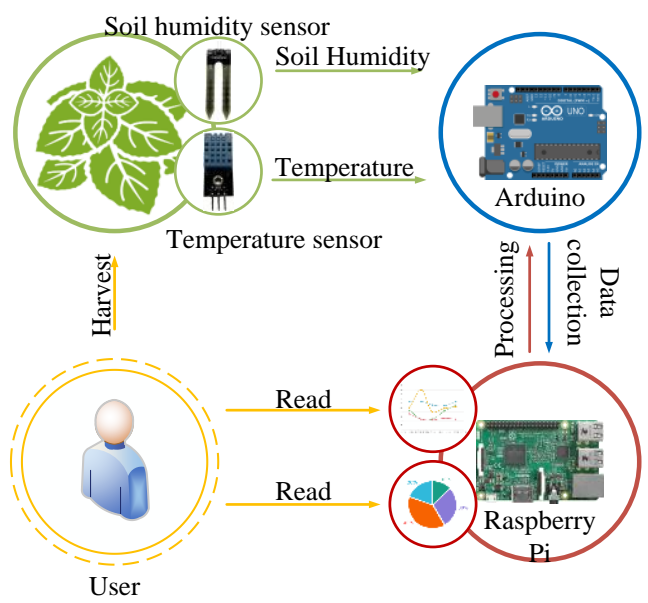

Figure 8. System design of APPD. 
Table 8. Data types of sensed data.

\begin{tabular}{ccccc}
\hline Attribute & Full Name & Data Type & Ranges & Mean \\
\hline ID & Identifier & Integer & & The serial number. \\
\hline temp & Temperature & Float & $0.0-40.0$ & $\begin{array}{c}\text { The environmental } \\
\text { temperature. }\end{array}$ \\
\hline mc & Moisture content & Float & $0.0-100.0$ & The soil water content. \\
\hline r & Red light & Integer & $0-255$ & The red beam component \\
of light.
\end{tabular}

Figure 9. XML-based message delivery in APPD.

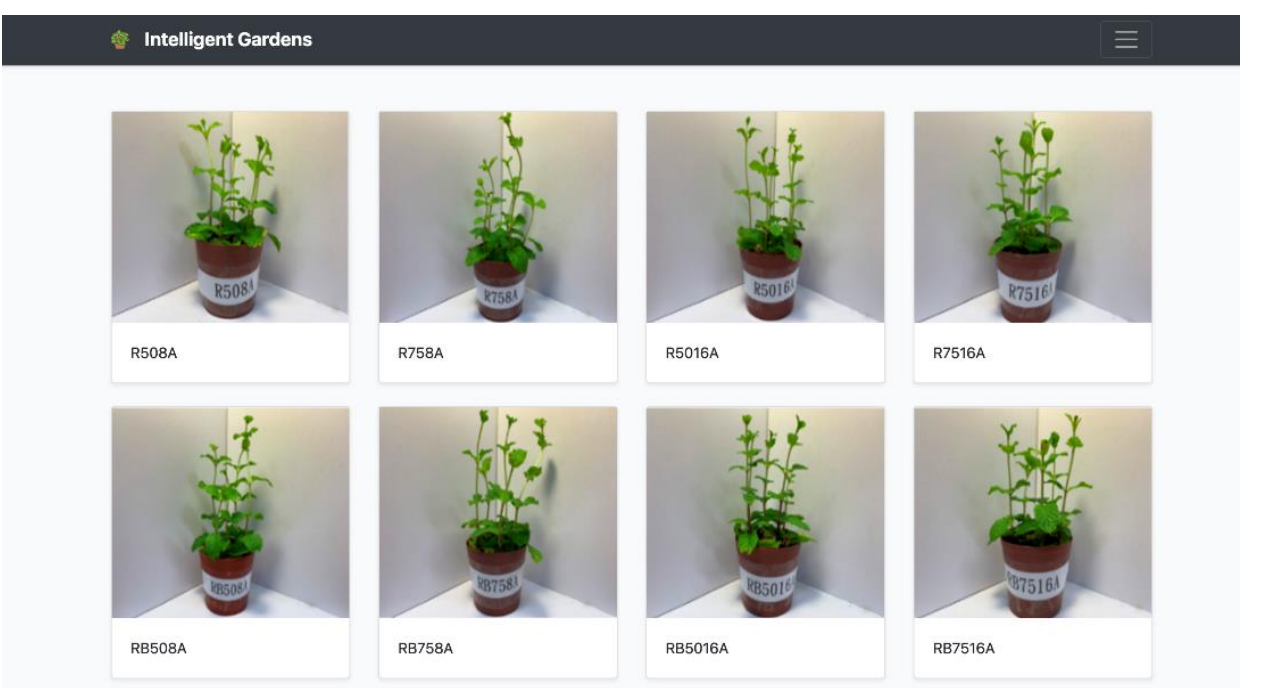

(a)

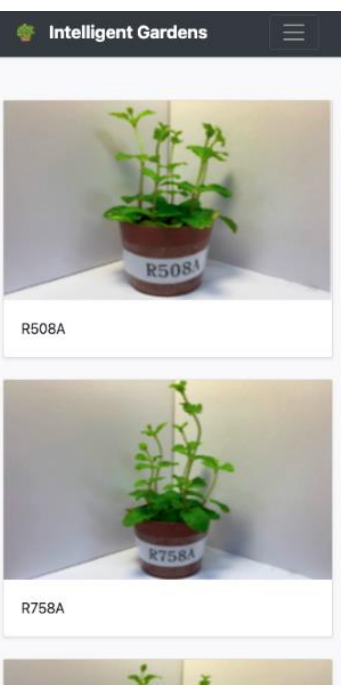

(b)

Figure 10. System interfaces of intelligent gardens for (a) a computer and (b) a smart phone. 
을 Intelligent Gardens

Dashboard
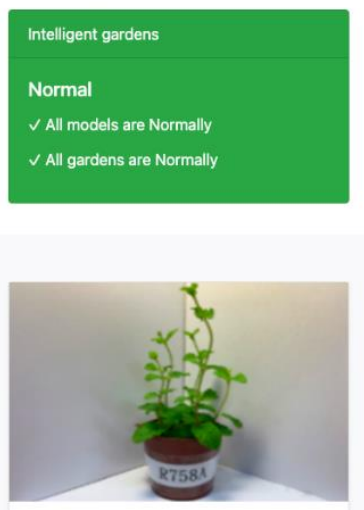

R758A

Red Light

Moisture content : $70 \%$
Light model

The model is functional
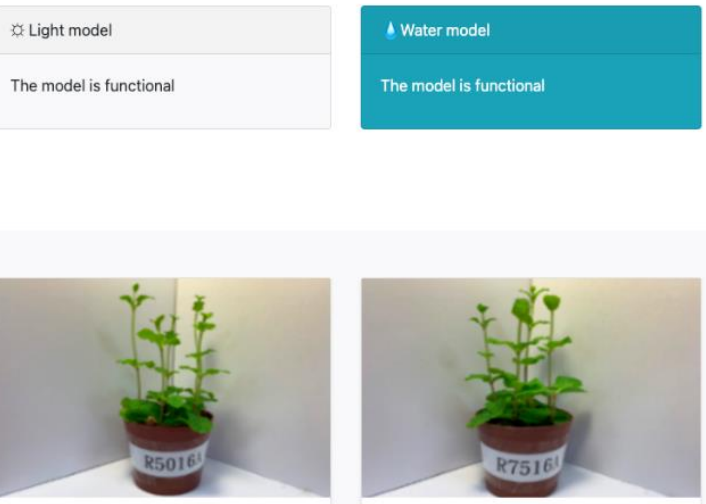

R5016A

Blue Light

Moisture content : $68 \%$

view
슬 Intelligent Gardens

Dashboard

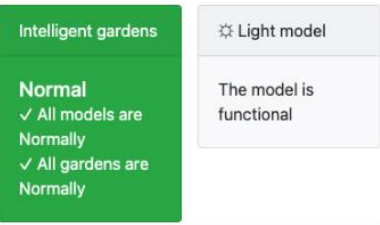

$\triangle$ Water model

The model is functional

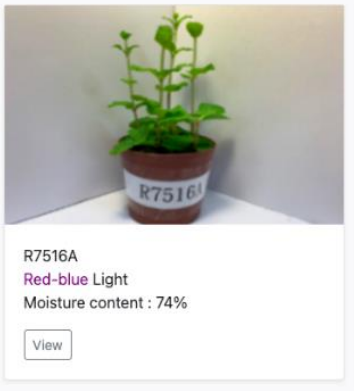

(a)

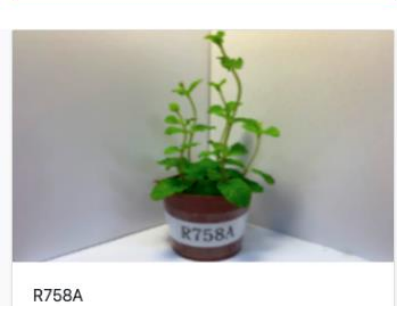

(b)

Figure 11. The real-time information of plants for (a) a computer and (b) a smart phone.

\section{Conclusions}

This study designs an Artificial Intelligence of Things (AIoT) based Plant Pot Design for planting edible mint in an office setting. APPD is composed of intelligent gardens and a cloud-based service platform. An intelligent garden deploys multiple AIoT sensors to monitor and control the growth of plant pots. The cloud-based service platform provides an inference engine and a data database with multiple triggers. An intelligent garden can easily be used to plant Mentha spicata using the Case-based Reasoning Mechanism. Five issues are considered and solved when designing intelligent gardens for an office setting, which are convenience, illuminance, photometric exposure, moisture content, and digitization. This study discusses eight growing statuses of edible mints with different illuminations, photometric exposures, and moisture contents. People can easily grow edible mints in an office setting. Evaluation results indicate that edible mints are with $16 \mathrm{~h}$ red-blue lighting and 50\% water content to make the maximum 5\% mint extract of the total weight of the mint leaves.

The limitation of this study is that only cultivation process factors for Mentha spicata are explored, including illumination, photoperiod exposure, moisture content, and temperature, in an office setting. Future research can be extended to AIoT detectors and other factors, such as soil nutrition in the agricultural aspect. The established system will be more in line with multiple and complex agriculture. Finally, four research aspects are proposed for researchers. (1) To design a plant-growth model deep-learning mechanism in which illumination, photoperiod exposure, moisture content, temperature, and soil nutrition will be taken in consideration. (2) To study the different cultivation modes between Mentha spicata and other mints, as well as the connection of plant-growth patterns and the amount of essential extract extracted in an office setting. (3) To study and find out plant-growth patterns related to parameters of the deployed AIoT sensors in an office setting. (4) To study and design a high-flexibility AIoT based Service-Oriented Architecture (SOA) to handle a large number of devices connected to the system, applied to large-scale plantings, small-scale plantings, or home plantings. 


\begin{abstract}
Author Contributions: Conceptualization, H.-H.K. and C.-H.L.; methodology, H.-H.K. and C.-H.L.; software, C.-H.L.; validation, H.-H.K., C.-H.L. and W.-C.W.; formal analysis, H.-H.K. and W.-C.W.; investigation, C.-H.L.; resources, C.-H.L.; data curation, C.-H.L.; writing-original draft preparation, H.-H.K. and C.-H.L.; writing-review and editing, H.-H.K. and W.-C.W.; supervision, H.-H.K.; project administration, H.-H.K.; funding acquisition, H.-H.K. All authors have read and agreed to the published version of the manuscript.
\end{abstract}

Funding: This research was funded by the Ministry of Science and Technology of the R.O.C. under the grant numbers MOST 110-2221-E-019 -057-MY2 and MOST 108-2813-C-019-033-B support this research.

Institutional Review Board Statement: Not applicable.

Informed Consent Statement: Not applicable.

Data Availability Statement: Not applicable.

Conflicts of Interest: The authors declare no conflict of interest.

\title{
References
}

1. Awad, M.M. An innovative intelligent system based on remote sensing and mathematical models for improving crop yield estimation. Inf. Processing Agric. 2019, 6, 316-325. [CrossRef]

2. Chehri, A.; Chaibi, H.; Saadane, R.; Hakem, N.; Wahbi, M.A. Framework of optimizing the deployment of IoT for precision agriculture industry. Procedia Comput. Sci. 2020, 176, 2414-2422. [CrossRef]

3. Rayhana, R.; Xiao, G.; Liu, Z. Internet of Things empowered smart greenhouse farming. IEEE J. Radio Freq. Identif. 2020, 4, 195-211. [CrossRef]

4. Dai, J.; Orsat, V.; Raghavan, G.V.; Yaylayan, V. Investigation of various factors for the extraction of peppermint (Mentha Piperita L.) leaves. J. Food Eng. 2010, 96, 540-543. [CrossRef]

5. Malayeri, S.H.; Hikosaka, S.; Goto, E. Effects of light period and light intensity on essential oil composition of Japanese mint grown in a closed production system. Environ. Control. Biol. 2010, 48, 141-149. [CrossRef]

6. He, F.; Zeng, L.; Li, D.; Ren, Z. Study of LED array fill light based on parallel particle swarm optimization in greenhouse planting. Inf. Processing Agric. 2019, 6, 73-80. [CrossRef]

7. Sabzalian, M.R.; Heydarizadeh, P.; Zahedi, M.; Boroomand, A.; Agharokh, M.; Sahba, M.R.; Schoefs, B. High performance of vegetables, flowers, and medicinal plants in a red-blue LED incubator for indoor plant production. Agron. Sustain. Dev. 2014, 34, 879-886. [CrossRef]

8. González-Briones, A.; Mezquita, Y.; Castellanos-Garzón, J.A.; Prieto, J.; Corchado, J.M. Intelligent multi-agent system for water reduction in automotive irrigation processes. Procedia Comput. Sci. 2019, 151, 971-976. [CrossRef]

9. Mason, B.; Rufí-Salís, M.; Parada, F.; Gabarrell, X.; Gruden, C. Intelligent urban irrigation systems: Saving water and maintaining crop yields. Agric. Water Manag. 2019, 226, 105812. [CrossRef]

10. Abbas, I.; Liu, J.; Faheem, M.; Shahzad Noor, R.; Shaikh, S.A.; Solangi, K.A.; Raza, S.M. Different sensor based intelligent spraying systems in agriculture. Sens. Actuators A Phys. 2020, 316, 112265. [CrossRef]

11. Lakhan, A.; Mohammed, M.A.; Ibrahim, D.A.; Abdulkareem, K.H. Bio-inspired robotics enabled schemes in blockchain-fog-cloud assisted IoMT environment. J. King Saud Univ.-Comput. Inf. Sci. 2021, 1-12. [CrossRef]

12. Podder, A.K.; Bukhari, A.A.; Islam, S.; Mia, S.; Mohammed, M.A.; Kumar, N.M.; Cengiz, K.; Abdulkareem, K.H. IoT based smart agrotech system for verification of Urban farming parameters. Microprocess. Microsyst. 2021, 82, 104025. [CrossRef]

13. Subahi, A.F.; Bouazza, K.E. An Intelligent IoT-based system design for controlling and monitoring greenhouse temperature. IEEE Access 2020, 8, 125488-125500. [CrossRef]

14. Tang, Y.; Jia, M.; Mei, Y.; Yu, Y.; Zhang, J.; Tang, R.; Song, K. 3D Intelligent supplement light illumination using hybrid sunlight and LED for greenhouse plants. Optik 2019, 183, 367-374. [CrossRef]

15. Farooqid, A.H.A.; Samgwan, N.S.; Sangwan, R.S. Effect of different photoperiodic regimes on growth, flowering and essential oil in Mentha Species. Plant Growth Regul. 1999, 29, 181-187. [CrossRef]

16. Hadipour, M.; FarrokhiDerakhshandeh, J.; Shiranc, M.A. An experimental setup of Multi-intelligent Control System (MICS) of water management using the Internet of Things (IoT). ISA Trans. 2020, 96, 309-326. [CrossRef]

17. Nawand, N.K.; Satpute, V.R. IoT based low cost and intelligent module for smart irrigation system. Comput. Electron. Agric. 2019, 162, 979-990. [CrossRef]

18. Brar, A.S.; Buttar, G.S.; Singh, M.; Singh, S.; Vashist, K.K. Improving bio-physical and economic water productivity of menthol mint (Mentha arvensis L.) through drip fertigation. Irrig. Sci. 2021, 39, 505-516. [CrossRef]

19. Durling, N.E.; Catchpole, O.J.; Grey, J.B.; Webby, R.F.; Mitchell, K.A.; Foo, L.Y.; Perry, N.B. Extraction of phenolics and essential oil from dried Sage (Salvia officinalis) using ethanol-water mixtures. Food Chem. 2007, 101, 1417-1424. [CrossRef]

20. Kung, H.Y.; Ku, H.H.; Wu, C.I.; Lin, C.Y. Intelligent and situation-aware pervasive system to support debris-flow disaster prediction and alerting in Taiwan. J. Netw. Comput. Appl. 2008, 31, 1-18. [CrossRef] 
21. Ku, H.H.; Chi, C.H. Ontology-based backpropagation neural network classification and reasoning strategy for NoSQL and SQL database. Int. J. Inf. Commun. Eng. 2017, 11, 1093-1097.

22. Diaz-Maroto, M.C.; Perez-Coello, M.S.; Cabezudo, M.D. Supercritical carbon dioxide extraction of volatiles from spices: Comparison with simultaneous distillation-extraction. J. Chromatogr. A 2002, 947, 23-29. [CrossRef]

23. Zheljazkov, V.D.; Cantrell, C.L.; Astatkies, T. Yield and composition of oil from Japanese cornmint fresh and dry material harvested successively. Agron. J. 2010, 102, 1652-1656. [CrossRef] 